\title{
Total oxidation of naphthalene using palladium nanoparticles supported on BETA, ZSM-5, SAPO-5 and alumina powders
}

Franciso J. Varela-Gandía a, Ángel Berenguer-Murcia ${ }^{a}$, Dolores Lozano-Castellóa, Diego Cazorla-Amorós $^{\mathbf{a}^{*}}$, David R. Sellick ${ }^{\mathrm{b}}$, Stuart H. Taylor ${ }^{\mathbf{b}^{* *}}$.

${ }^{a}$ Departamento de Química Inorgánica, Universidad de Alicante, Ap. 99, E-03080, Alicante, Spain

${ }^{b}$ Cardiff Catalysis Institute, School of Chemistry, Cardiff University, Main Building, Park Place, Cardiff CF10 3AT, UK.

\begin{abstract}
A range of catalysts based on Pd nanoparticles supported on inorganic supports such as BETA and ZSM-5 zeolites, a silicoaluminophosphate molecular sieve (SAPO-5) and $\gamma$ alumina as a standard support have been tested for the total oxidation of naphthalene (100ppm, total flow $50 \mathrm{ml} / \mathrm{min}$ ) showing a conversion to carbon dioxide of $100 \%$ between $165-180^{\circ} \mathrm{C}$ for all the analysed catalysts. From the combined use of zeolites with PVP polymer protected Pd based nanoparticles, enhanced properties have been found for the total abatement of naphthalene in contrast with other kinds of catalysts. A Pd/BETA catalyst has been demonstrated to have excellent activity, with a high degree of stability, as shown by time on line experiments maintaining $100 \%$ conversion to $\mathrm{CO}_{2}$ during the 48 hours tested.
\end{abstract}

Keywords: Catalytic oxidation; Zeolite BETA; ZSM-5; Pd Nanoparticles; Naphthalene

* Corresponding author: e-mail address: cazorla@ua.es

FAX: (+34)965903454; Telephone: (+34) 965903946

**Corresponding author: e-mail address: taylorsh@cf.ac.uk 


\section{Introduction}

Polycyclic aromatic hydrocarbons (PAHs) are a family of volatile organic compounds (VOCs) produced mainly during combustion processes of organic matter [1,2]. PAH emissions originate from a great variety of sources, such as incomplete fuel combustion, diesel or gasoline, internal combustion engines, asphalt transformation plants or coal and wood powered plants [3, 4]. According to the Environmental Protection Agency (EPA), a list containing 16 PAHs has been established as major pollutants whose emission must be controlled [5]. PAH compounds are mainly formed by several aromatic rings such as naphthalene (two-ring PAH), phenanthrene (three-ring PAH), pyrene or chrysene (four-ring $\mathrm{PAH}$ ) or benzo[ghi]perylene (five-ring $\mathrm{PAH}$ ). PAH composition differs depending on the emission source, and for example, PAHs found in diesel emissions mainly consist of two to five aromatic rings, and include naphthalene, phenanthrene, pyrene and fluoranthene [6,7]. The main reason to reduce PAH emissions is that they have now been identified as a serious environmental and health risk, due to their carcinogenic and/or mutagenic properties $[8,9]$. Naphthalene is the simplest and least toxic of the PAHs and it is thus used as a model compound for this group of pollutants.

The development of technologies to reduce atmospheric pollution has increased in recent years. Methods such as biodegradation, high-energy electron beam irradiation, ozonization, adsorption, thermal incineration or catalytic oxidation have been employed to reduce the level of PAHs [2, 10-15]. Despite the numerous options, catalytic oxidation to produce carbon dioxide and water is the most promising technology due to its lower operating temperature and/or higher selectivity to $\mathrm{CO}_{2}[4,16]$.

Several studies have been performed to investigate the catalytic combustion of PAHs. Zang et al. [6] have utilized noble metal catalysts supported on $\gamma$-alumina, indicating that precious 
metal catalyst such as Pd or Pt, were the most active in oxidising naphthalene. Garcia et al. [16] studied the total oxidation of VOCs, such as propane, benzene and naphthalene, with catalysts based on vanadium oxide, palladium oxide and mix Pd/V-supported on titania. Whilst for the case of aliphatic and one-ring aromatic compounds, $\mathrm{Pd} / \mathrm{V} / \mathrm{TiO}_{2}$ was very promising, but $\mathrm{Pd} / \mathrm{TiO}_{2}$ was the most active for the total oxidation of naphthalene. On the other hand, a study of naphthalene combustion over a wide range of metal oxide catalysts, based on $\mathrm{Co}, \mathrm{Mn}, \mathrm{Cu}, \mathrm{Fe}$, Ceand $\mathrm{Ti}$, have been carried out, establishing that nanocrystalline ceria was the most efficient catalyst for naphthalene removal [17]. In reference to zeolites, Neyestanaki et al. [18] have prepared metal exchanged zeolites for the removal of naphthalene in gas mixtures, simulating the emission from combustion biofuels by catalytic oxidation. In more recent developments, mesoporous cerium oxides have also been prepared by nanocasting and they demonstrate appreciable activity for the total oxidation of naphthalene [4].

Despite all these previous studies, PVP polymer protected metal nanoparticles supported on inorganic oxides supports such as alumina or zeolites have not been studied yet for this reaction. During the last ten years, significant efforts have been dedicated to the preparation of nanoparticles. Their preparation, structure, characterization and applications are issues of great current interest [19], with particular attention paid to the importance of their size and structure. Focusing on Pd nanoparticles, Teranishi et al. [20] dealt with the fundamental aspects of monometallic palladium nanoparticles, their synthesis and structural control, and the system has played an important role as a catalyst in numerous organic reactions. Within this field, unsupported Pd based nanoparticles have been used successfully in our group in the semi-hydrogenation of phenylacetylene [21] or supported on carbon [22] or inorganic materials [23]. Recently, Pd nanoparticles supported on $\gamma$-alumina have been successfully used in the PrOx reaction [24], indicating the benefits of using PVP polymer protected Pd 
nanoparticles instead of Pd catalysts prepared by classical methods such as impregnation with a Pd compound and further reduction in hydrogen atmosphere.

Against this background, we have studied the use of powder catalysts based on Pd nanoparticles supported on two different zeolites (BETA and ZSM-5), a molecular sieve SAPO-5, and a more conventional $\gamma$-alumina support for the total oxidation of naphthalene. Special attention has been paid to the recyclability and stability of the catalyst over extended time-on-stream experiments. Catalysts have been characterised before and after use and this is important for assessing catalyst lifetime and stability.

\section{Experimental}

\subsection{Catalyst preparation}

Four supported catalysts were prepared by deposition of palladium nanoparticles onto selected inorganic supports. Pd nanoparticles protected by polyvinylpirrolidone (PVP) were synthesised using the reduction-by-solvent method previously described [24]. Four inorganic supports were used:

(1) The powder $\gamma$-alumina support was provided from Alfa Aesar 99.97\% (Ref. 039812).

(2) Two zeolites, BETA and ZSM-5. The procedure followed for the synthesis of these materials has been described elsewhere [25].

(3) A silicoaluminophosphate molecular sieve SAPO-5 was prepared following the method described by Campelo et al [26].

The catalysts used in this work were prepared by the impregnation method, as reported previously by our group [22-24]. In a typical procedure, $3 \mathrm{~g}$ of support was mixed with the appropriate amount of the purified colloidal suspension to yield $1 \mathrm{wt}$ \% of metallic loading. The solution was stirred for two days at room temperature in order to ensure a similar load and dispersion for the different catalysts, and transferred to an oven, where it was left at $60^{\circ} \mathrm{C}$ 
in order to evaporate the solvent. The catalysts were then washed several times with a cold mixture of $\mathrm{H}_{2} \mathrm{O} / \mathrm{EtOH}\left(50: 50\right.$, v/v), and left to dry overnight at $60{ }^{\circ} \mathrm{C}$.

\subsection{Catalyst characterisation.}

ZSM-5 and BETA zeolites and SAPO-5 silicoaluminophosphate molecular sieve were characterised by XRD, using a 2002 Seifert powder diffractometer. The scanning rate was $2^{\circ} / \mathrm{min}$ and $\mathrm{Cu}-\mathrm{K} \alpha$ radiation was used.

TEM images of the catalysts were recorded in aJEOL (JEM-2010) electron microscope equipped with an EDS analyzer (OXFORD, model INCA Energy TEM 100) operating at 200 $\mathrm{kV}$ with a space resolution of $0.24 \mathrm{~nm}$. For the analysis, a small amount of the catalyst was suspended in a few drops of methanol, and sonicated for a few minutes. A drop of this suspension was then deposited onto a 300mesh Lacey copper grid and left to dry at room temperature. The diameter of the nanoparticles and the dispersion of the metal over the catalyst were determined as described previously [24].

The textural characterization of the catalysts was carried out by means of the adsorption of $\mathrm{N}_{2}$ at $-196{ }^{\circ} \mathrm{C}$ and $\mathrm{CO}_{2}$ at $0{ }^{\circ} \mathrm{C}$ (Autosorb 6, Quantachrome). Prior to the adsorption measurements, the catalysts were outgassed under vacuum $\left(10^{-2} \mathrm{mbar}\right)$ at $250{ }^{\circ} \mathrm{C}$ for $4 \mathrm{~h}$ to remove any adsorbed impurities. Surface area was calculated from nitrogen adsorption isotherms using the BET equation (SBET). Total micropore volume $\left(V_{\mathrm{DR}}\left(\mathrm{N}_{2}\right)\right)$ and narrow micropore volume $\left(V_{\mathrm{DR}}\left(\mathrm{CO}_{2}\right)\right)$ were calculated by applying the Dubinin-Radushkevich (DR) equation to the $\mathrm{N}_{2}$ adsorption data at $-196{ }^{\circ} \mathrm{C}$ and the $\mathrm{CO}_{2}$ adsorption data at $0{ }^{\circ} \mathrm{C}$, respectively [27].

The metal loading of the catalysts was analyzed by inductively coupled plasma-optical emission spectroscopy (ICP-OES), in a PerkinElmer Optima 4300 system. The extraction of the metal was made by an oxidative treatment of the samples with aqua regia, followed by 
filtration of the remaining solid using a nylon membrane filter (average pore diameter of 400 $\mathrm{nm}$ ) and dilution of the resulting metal solution using a volumetric flask.

XPS measurements were made on an Omicron ESCA+ photoelectron spectrometer using a non-monochromatized $\mathrm{MgKaX}$-ray source $(\mathrm{h} v=1253.6 \mathrm{eV})$. An analyser pass energy of 50 $\mathrm{eV}$ was used for survey scans and $20 \mathrm{eV}$ for detailed scans. Binding energies are referenced to the C1s peak assumed to have a binding energy of $284.5 \mathrm{eV}$.

Thermogravimetric analysis (TGA) experiments were performed in a Thermogravimetric Analyzer (TA Instruments, model SDT 2960). In these experiments, approximately $10 \mathrm{mg}$ of the catalyst (fresh and used) were treated. The catalyst was heated up to $900^{\circ} \mathrm{C}$ (heating rate of $10^{\circ} \mathrm{C} / \mathrm{min}$ ) and equilibrated for $1 \mathrm{~h}$, under a constant flow rate of $100 \mathrm{ml} / \mathrm{min}$ air.

\subsection{Catalyst testing}

Catalytic activity tests for naphthalene oxidation were carried out in a fixed bed reactor (diameter: $1.6 \mathrm{~cm}$ ). The feed stream consisted, in all cases, of $100 \mathrm{vppm}$ naphthalene in a mixture of $20 \% \mathrm{O}_{2}$ and $80 \%$ He. The total flow (F) was set to $50 \mathrm{ml} / \mathrm{min}$ and a catalyst powder weight $(\mathrm{m})$ of $200 \mathrm{mg}(\mathrm{F} / \mathrm{m}=15 \mathrm{~L} / \mathrm{g} \cdot \mathrm{h})$. Analysis of reactants and reaction products was performed by on-line gas chromatography using thermal conductivity and flame ionization detectors. Catalytic activity was measured over the temperature range $100-200^{\circ} \mathrm{C}$ in incremental steps and temperatures were measured by a thermocouple placed in the catalyst bed connected to a PID controller. Data were collected at each temperature after a stabilization time of 20 minutes. Three analyses were made at each temperature to ensure that steady state data were collected. Oxidation activity is expressed as a yield of carbon dioxide. Furthermore, time-on-line experiments for long-term use of these catalysts were performed with the aim to probe possible deactivation. For this purpose, the catalysts were tested using 
reaction conditions the same as described above but at a higher temperature of $250^{\circ} \mathrm{C}$ for 48 h.

\section{Results and discussion}

\subsection{Catalysts characterisation.}

Firstly, the as synthesised materials, BETA, ZSM-5 and SAPO-5 were characterized by $\mathrm{XRD}$, confirming the typical structure for each material. Moreover, after the impregnation method, the catalysts were analysed by XRD and no change was observed in the prepared catalysts (results not shown), indicating that the process of introducing the Pd nanoparticles did not compromise the structure of the supports.

Nitrogen adsorption was performed to investigate the porous texture of the as prepared materials, and any changes that may have occurred due to nanoparticle deposition during catalyst preparation. From the $\mathrm{N}_{2}$ isotherms (results not shown), it is possible to confirm that BETA, ZSM-5 and SAPO-5 exhibit a Type I isotherm, which according to IUPAC classification [28] is typical of microporous solids. $\gamma-\mathrm{Al}_{2} \mathrm{O}_{3}$ shows a Type II isotherm [28] typical of macroporous materials. After preparing the catalyst, the adsorption/desorption isotherms of the catalysts did not exhibit any noticeable change in the isotherm shape, indicating that although the adsorbed amounts decreased for all the prepared catalysts, with respect to the original support, none of the samples showed evidence for loss of porosity or creation of new porosity. Table 1 summarizes the surface areas $\left(S_{\mathrm{BET}}\right)$, the total micropore volume $\left(V_{\mathrm{DR}}\left(\mathrm{N}_{2}\right)\right)$ and narrow micropore volume $\left(V_{\mathrm{DR}}\left(\mathrm{CO}_{2}\right)\right)$. Analysing the results in depth, it can be established that the catalyst preparation method has affected the porosity of the supports. According to the $\mathrm{N}_{2}$ adsorption isotherms the amount of $\mathrm{N}_{2}$ adsorbed on the catalysts diminished in all cases with respect to the supports alone (See $S_{\mathrm{BET}}$ and $V_{\mathrm{DR}}\left(\mathrm{N}_{2}\right)$ in Table 1). Pd/BETA and Pd/ZSM-5 showed reduced adsorption properties to a minor extent. Nevertheless, the Pd/SAPO-5 catalyst showed a considerably reduced apparent surface area 
while still being a microporous material as mentioned previously. The $\mathrm{Pd} / \gamma-\mathrm{Al}_{2} \mathrm{O}_{3}$ catalyst had reduced specific BET surface area, although it is a macroporous material. Therefore, it can be ascertained that the catalyst preparation method affects the porous texture, especially the microporosity. This occurred to a minor degree for BETA and ZSM-5 supports, but to a more significant extent for the SAPO-5 support.

Figure 1 shows the TEM images of the Pd colloid together with the four catalysts prepared for this work. As can be extracted from the TEM micrographs of the colloid, the synthesised colloid shows very low polidispersity for the size of the particles. From the different images of the different catalysts prepared for this work, the deposition of polymer-protected nanoparticles results in a noticeable change in Pd particle size, which agrees with our previous studies [22-24]. Therefore, TEM micrographs show an effect on the size of the particles during catalyst preparation, as the mean particle size slightly increases from the starting colloid to the final catalyst. Table 2 shows the diameter of the prepared particles (d) before and after deposition on the supports and the dispersion (D) of the nanoparticles, calculated according to a procedure described in detail elsewhere, assuming a spherical particle shape [29]. Metal loading (wt \%) calculated by ICP analyses are included in Table 2. The Pd loading of the catalysts varies by nearly a factor of 2 . The reason for such a difference is not straightforward and must be related to both the surface roughness of the supports and to the interaction among the polymer-protected Pd nanoparticles and the support.

\subsection{Catalytic performance for naphthalene oxidation.}

The catalytic activity for naphthalene oxidation was measured for the four catalysts. Four cycles of increasing and then reducing reaction temperature were performed with each catalyst in order to ensure the stability of the sample. The main reaction product observed for naphthalene oxidation was $\mathrm{CO}_{2}$. Nevertheless, by-products such as phthalic anhydride, 
naphthanol, ketone, benzoic acid and 1,2-dibenzoic acid were also detected in very low concentrations under certain reaction conditions when conversion was relatively low. These compounds were trapped in acetone using an acetone/ice cold trap at the exit of the reaction system and then analyzed by GC-MS. The reaction temperature was fixed between 150$165^{\circ} \mathrm{C}$, depending on the catalyst, and products collected for $2 \mathrm{~h}$. In addition, it is worth noting that $\mathrm{CO}$ was not detected as a reaction product in any of the experiments performed.

Table 3 shows the temperature required for total naphthalene oxidation to $\mathrm{CO}_{2}$ for each catalyst over the four temperature cycles. Excellent catalytic performance has been observed for each of the four catalysts. Analyzing these results thoroughly, Pd/BETA and Pd/ZSM-5, show a lower temperature for total naphthalene conversion, whilst Pd/SAPO-5 and Pd/ $\gamma$ $\mathrm{Al}_{2} \mathrm{O}_{3}$ are able to reach full naphthalene conversion at slightly higher temperatures. For comparative purposes, the activity of the support for the most active catalyst was measured. BETA zeolite was only active at temperatures above $300^{\circ} \mathrm{C}$, reaching a conversion to $\mathrm{CO}_{2}$ of $64 \%$ at $350^{\circ} \mathrm{C}$. Hence the zeolite support without the Pd nanoparticles was totally inactive over the temperature range where the Pd-based catalyst showed total naphthalene conversion.

The Arrhenius plots for the first reaction cycle test for all catalysts were plotted (results not shown). The linearity of this plot at low conversions $(<20 \%)$ indicated that the reaction is in the chemical kinetic regime and that there were no diffusional limitations in the reaction tested. Table 4 includes the turnover frequency (TOF) and the apparent activation energy $\left(\mathrm{E}_{\mathrm{a}}\right)$ for the four catalysts tested during the first catalytic reaction cycle. For comparison purposes, the $\mathrm{TOF}$ for a $0.5 \% \mathrm{Pt} / \mathrm{SiO}_{2}$ catalysts tested previously in the same reaction under very similar conditions [30] has been included. Interestingly, despite being the same Pd-PVP nanoparticles in all the catalysts tested, the TOF and $E_{a}$ is different depending on the support, reaching $\mathrm{E}_{\mathrm{a}}$ values for the $\mathrm{Pd} / \gamma-\mathrm{Al}_{2} \mathrm{O}_{3}$ which are four times that found for the $\mathrm{Pd} / \mathrm{BETA}$ catalyst. Therefore, close inspection of the influence of the support is necessary to explain the 
different activity data for the four catalysts tested. Comparing our results with the different catalysts tested with one prepared by classical impregnation, $\mathrm{Pt} / \mathrm{SiO}_{2}$ [30], it is possible to observe that the Pd-PVP nanoparticles based catalysts have a better activity that Pt-based catalysts, indicating the usefulness of this kind of nanomaterials which can be easily tuned during the preparation method to adapt their properties to the desired reaction. Then, with the aim to explain the different behaviour of the catalyst tested, special attention should be paid to the influence of the support in the catalytic reaction. In this respect, supports which strong surface acidity may favour the naphthalene oxidation reaction when used in conjunction with Pd-PVP nanoparticles.

The higher activity of the ZSM-5 and BETA catalysts may be associated with the porosity of the catalyst. Thus, Pd/BETA and Pd/ZSM-5 both present a significant surface area that may have an influence on the activity during the total oxidation, and therefore, there may be a relationship between the apparent surface area of the catalyst and its capacity to oxidize naphthalene. Moreover, the pore size distribution and channel interconnectivity may also have an important contribution, in agreement with Puertolas et al. [4], who studied the use of different mesoporous cerium oxides prepared through a nanocasting method for the total oxidation of naphthalene, mentioning that wider pore size distributions and pore interconnectivity could facilitate the total oxidation of naphthalene. In this sense, the zeolite supports BETA and ZSM-5, which have a three-dimensional pore size distribution, present a high interconnectivity, in contrast to SAPO-5 acting as a support which presents a onedimensional porosity with a larger pore size than zeolites BETA or ZSM-5. Considering the pore size of the selected supports, it is clear that the Pd nanoparticles will be deposited solely on the outer surface of the microporous zeolites and silicoaluminophosphate, whereas in the case of the macroporous support $\left(\gamma-\mathrm{Al}_{2} \mathrm{O}_{3}\right)$ the nanoparticles will be deposited both in the inner and outer surface. The location of the particles indicates that while the inner surface 
area of the selected supports does not play a significant role in the oxidation of naphthalene as such, it clearly influences the outcome of the catalytic reaction. The supports with a larger surface area, in this respect, may adsorb larger amounts of naphthalene in their porous structure, thus acting as "naphthalene reservoirs" which feed the Pd particles where the catalytic oxidation takes place, which could help to explain our results.

It is well known that BETA zeolite has a relatively high external surface area resulting from its structure being the combination of two intergrown polymorphs. This high external surface area may result in increased accessibility for naphthalene molecules to reach the $\mathrm{Pd}$ nanoparticles of the catalyst, as well as a possible reservoir for naphthalene molecules. As a consequence, total oxidation of naphthalene to $\mathrm{CO}_{2}$ can be reached at lower temperatures. It is also possible that the adsorption of naphthalene onto the catalysts could be significant and could provide a reservoir for naphthalene. In order to verify this, the Pd/BETA, Pd/ZSM-5 and Pd/SAPO-5 catalysts were tested under the same conditions as the aforementioned oxidation experiments, but without $\mathrm{O}_{2}$ in the reactant flow, in order to study the contribution of the catalyst towards naphthalene adsorption. The catalyst $\mathrm{Pd} / \gamma-\mathrm{Al}_{2} \mathrm{O}_{3}$ was excluded from this experiment, because from the catalytic oxidation experiments it became evident that the $\mathrm{Pd} / \gamma-\mathrm{Al}_{2} \mathrm{O}_{3}$ catalyst did not exhibit any significant naphthalene adsorption during the reaction time of about $1 \mathrm{~h}$ and at the lowest temperature used. That is, naphthalene in the gas stream leaving the reactor at this temperature contained $96 \mathrm{ppm}$ of naphthalene, which corresponds to $96 \%$ of the initial concentration in the inlet stream. Figure 2 shows the amount of naphthalene adsorbed by the different catalysts during a time similar to that used in the experiments in the presence of oxygen and over the temperature range studied. According to these results, the amount of adsorbed naphthalene in Pd/SAPO-5 is lower when compared with the zeolite based-catalysts. Furthermore, there is no appreciable naphthalene adsorption above $150^{\circ} \mathrm{C}$. On the contrary, Pd/BETA and Pd/ZSM-5 present a much larger adsorption 
capacity for naphthalene at higher temperatures. This adsorbed naphthalene may act as a "reservoir" to feed the catalysts in the initial stages of the reaction, thus increasing the efficiency of the catalyst. Considering this feature, Pd/BETA and Pd/ZSM-5 may permit naphthalene oxidation at lower temperatures than Pd/SAPO-5. Therefore, the three dimensional pore structure and the high adsorption capacity seem to play an important role in the performance of the catalyst.

Although Pd/BETA was the most active catalyst after four cycles, another outstanding feature was the reduction of the temperature at which total conversion to $\mathrm{CO}_{2}$ was achieved as the number of cycles was increased, whilst the temperature for total oxidation for Pd/ZSM-5 remains unchanged after four cycles. This could be explained by considering that in the case of the Pd/BETA catalyst there was coke deposition during the first cycle (evident by a change of colour from grey to black upon completion of the first catalytic cycle). As the catalyst was used coke deposition was reduced, producing naphthalene oxidation to $\mathrm{CO}_{2}$ at lower temperatures. In this sense, our results reveal that the amount of coke deposited after 4 cycles (see Table 3) does not affect the catalytic activity of the studied systems in terms of deactivation.

Another parameter that can have an influence on the catalytic activity is the stability of the samples. Figure 3 shows the variation of the catalytic activity (expressed as conversion to $\mathrm{CO}_{2}$ ) for naphthalene oxidation, as a function of the reaction temperature. According to these results, the catalytic activity for Pd/BETA, Pd/ZSM-5 and Pd/SAPO-5 remained unchanged after four cycles and maintained high naphthalene oxidation activity towards the formation of $\mathrm{CO}_{2}$. In contrast, $\mathrm{Pd} / \gamma-\mathrm{Al}_{2} \mathrm{O}_{3}$ showed an increase in the temperature for total oxidation after the completion of the four cycles and this can tentatively be attributed to the deactivation of the catalyst. With the aim to distinguish differences between deactivation of these three catalysts, it is necessary to analyse their behaviour at intermediate temperatures. Therefore, in 
order to probe potential deactivation, catalytic activity at $150^{\circ} \mathrm{C}$ is summarized in Table 5 . Despite appearing to be relatively stable after four temperature cycles, the yield of $\mathrm{CO}_{2}$ during incomplete conversion at $150^{\circ} \mathrm{C}$ can provide further information on which is the most suitable for naphthalene total oxidation. Consequently, focusing our attention on these values the Pd/BETA catalyst is not affected after four cycles, while Pd/ZSM-5 and Pd/SAPO-5 showed reduced overall conversion after four catalytic cycles, this decrease being more moderate for Pd/SAPO-5 and more pronounced for Pd/ZSM-5.

TEM analyses were performed on the used catalysts after reaction, with the aim to analyse any significant effect of the reaction conditions on the catalyst. Figure 4 illustrates the TEM micrographs of the four used catalysts and the diameter of the Pd particles (d) and the dispersion of the catalysts (D) after the reaction cycles included in Table 6. From the TEM analysis it can be concluded that all the Pd nanoparticles in the catalysts have increased in size. Despite this increase in particle size, only the Pd/alumina catalyst has shown a significant increase in the temperature for total oxidation after four cycles. Therefore, the rest of the catalysts have demonstrated high stability for oxidation of naphthalene and the increase of Pd particle size has not had a major detrimental effect on activity.

XPS analyses were performed on the fresh and used catalysts. Table 7 shows the results corresponding to the atomic percentage of the different Pd species present on the catalyst surface and the binding energy of each of the species determined through curve fitting. The XPS binding energies revealed the presence of two peaks corresponding to the $3 d_{3 / 2}$ and $3 d_{5 / 2}$ transitions. In the case of prepared samples, the presence of Pd (II) on the surface of the Pd nanoparticles is attributed to the carbonyl function of the protecting polymer interacting with the metallic palladium, removing electron density from the surface, as has been established in our previous work [24] and by Somorjaiet al. for Pt nanoparticles capped with this kind of agent [31-33]. In short, what appears in this case as Pd(II) in the XPS spectra, is attributed to 
the palladium atoms on the surface of the nanoparticle, which are electron deficient due to their interaction with the protecting polymer. Following on, the greater amount of Pd (II) present in the Pd/BETA with respect to the other catalysts could be due to a stronger interaction of Pd with PVP than for PVP with the support, which in turn may affect the catalytic activity. In contrast, $\mathrm{Pd} / \mathrm{ZSM}-5, \mathrm{Pd} / \mathrm{SAPO}-5$ and $\mathrm{Pd} / \gamma-\mathrm{Al}_{2} \mathrm{O}_{3}$ catalysts have a stronger PVP-support interaction that produces a reduction in the electronic density withdrawn and therefore, the quantity of Pd (0) is higher. Once all the catalysts were tested, the amount of Pd (II) increased in all the catalysts except on the surface of the Pd/BETA catalyst, indicating that the $\mathrm{Pd} /$ nanoparticles were partially oxidised, producing $\mathrm{Pd}(\mathrm{II})$ species on the $\mathrm{Pd}$ nanoparticle surface. On the one hand it could be stated that the Pd nanoparticle is protected by the PVP due to a stronger interaction of Pd with PVP and this makes the Pd nanoparticle more resistant towards oxidation. On the other hand, the Pd/BETA catalyst increased the intensity of the Pd (0) signal. This phenomenon could be attributed to the Pd/BETA catalyst being more stable due to the aforementioned stronger interaction between the $\mathrm{Pd}$ nanoparticles and the protecting polymer. The importance of the protection can be better assessed upon analyzing the conversion of naphthalene at $150^{\circ} \mathrm{C}$ (see Table 5). Thus, despite having the lowest $\mathrm{Pd}(0) / \mathrm{Pd}(\mathrm{II})$ ratio in the fresh catalyst, the PVP-Pd interaction explains the absence of deactivation of this catalyst as the sample is submitted to successive reaction cycles. On the contrary, the rest of the prepared catalysts, which have a higher initial $\mathrm{Pd}(0) / \mathrm{Pd}(\mathrm{II})$ ratio, have a lower conversion at $150^{\circ} \mathrm{C}$ (see Table 5) because the interaction between the Pd nanoparticles and the protecting polymer is less intense than the Pd/BETA catalysts, rendenring them more susceptible to surface oxidation. Another possible reason that could be preventing Pd nanoparticle oxidation is associated with the coke deposition produced on the Pd/BETA catalyst. Apart from zeolite BETA acting as a cracking catalyst, the Pd (II) produced onthe surface is being reduced due to this enhanced effect between the 
Pd nanoparticles and BETA zeolite that can promote the reduction of Pd (II) at the surface to Pd (0) and the oxidation of part of this deposited coke. Therefore, the Pd/BETA catalyst has different behaviour, making it more stable than the rest of the catalysts.

The Pd/BETA catalyst was identified as the most effective metal-supported catalyst for naphthalene total oxidation. Therefore, long-term use of this catalyst, in order to start to evaluate the catalyst life time, was performed. Earlier studies indicated that activity was stable and the catalyst was able to produce total naphthalene conversion at low temperatures between $165-180^{\circ} \mathrm{C}$. An additional accelerated ageing stability study was conducted at $250^{\circ} \mathrm{C}$ for 48 h. Figure 5 shows the time-on-line data for the Pd/BETA catalyst. It was evident that the catalyst was stable for at least $48 \mathrm{~h}$, and there was no evidence for any catalyst deactivation over the test period. The yield of $\mathrm{CO}_{2}$ at the beginning of the experiment was $100 \%$ and it was not diminished after $48 \mathrm{~h}$. Although the Pd/BETA was the best catalyst, the time-on-line activity of Pd/ZSM-5 was also analyzed in the same manner and it showed equally stable $100 \%$ conversion to $\mathrm{CO}_{2}$ over the reaction time (results not shown).

With respect to naphthalene total oxidation, in the literature it is possible to find several research studies focused on using metal supported catalysts, prepared by conventional methods, or metal oxide catalysts for naphthalene oxidation. Neyestanaki et al. [18] have studied the use of ZSM-5 impregnated with different concentrations of Pd to remove the emission of pollutants from the combustion of biofuels. In this study, the catalysts were used for four consecutive cycles, with three different gas mixtures varying the composition of different polluting gases including always $50 \mathrm{ppm}$ of naphthalene. In terms of naphthalene conversion, it can be seen that our catalyst based on Pd nanoparticles exhibits a naphthalene total conversion between $165-180^{\circ} \mathrm{C}$. Meanwhile, the catalyst prepared by the impregnation method from the aforementioned work needed a temperature of $400^{\circ} \mathrm{C}$ to achieve total conversion for the Na-form of the ZSM-5 zeolite. On the other hand, the H-form of the ZSM- 
5 reduced the temperature for total conversion to $200^{\circ} \mathrm{C}$, however, catalyst deactivation was observed. Also using a Pd-based catalyst, Zang et al. [6] studied the oxidative decomposition of naphthalene (100 ppm) by a supported $\mathrm{Pd} / \gamma-\mathrm{Al}_{2} \mathrm{O}_{3}$ catalyst, and it demonstrated $90 \%$ conversion to $\mathrm{CO}_{2}$ at $285^{\circ} \mathrm{C}$, but total conversion was not reached until approximately $400^{\circ} \mathrm{C}$. Furthermore, Garcia et al. [16] studied the total oxidation of naphthalene (100 ppm) with a $\mathrm{Pd} / \mathrm{TiO}_{2}$ catalyst, which produced a total conversion to $\mathrm{CO}_{2}$ at approximately $270^{\circ} \mathrm{C}$, which was a lower temperature than Zang et al. [6]. In addition, it was reported that naphthalene physisorption on the catalyst had an important role in the catalyzed reaction with $\mathrm{Pd} / \mathrm{TiO}_{2}$. Therefore, our catalysts supported on zeolites based on PVP stabilized Pd nanoparticles appear to be more stable than those prepared by conventional impregnation methods, and the total conversion to $\mathrm{CO}_{2}$ is achieved at lower temperatures.

Comparing our results with those obtained with other kinds of catalysts, it is possible to observe that the total oxidation of naphthalene is reached at lower temperatures with our zeolite supported catalysts. In the case of metal oxide catalysts [7] such as $\mathrm{CeO}_{2}$ or mixed oxides (CuZnO) full conversion is reached at temperatures between $250^{\circ} \mathrm{C}$ and $270^{\circ} \mathrm{C}$, respectively. Whilst for the case of metals supported on different oxides such as $\mathrm{Pt} / \mathrm{SiO}_{2}$ [33] the optimum temperature for naphthalene oxidation was $250^{\circ} \mathrm{C}$. Shie et al. [34] indicated that $\mathrm{Pt} / \gamma$-alumina decreased the reaction temperature for $95 \%$ naphthalene total oxidation to $207^{\circ} \mathrm{C}$. On the other hand, Pt supported on mesoporous materials have also been used. Park et al. [35] have prepared Pt/MCM41 and Pt/SM41 (SM: molecular sieve) and used them as catalysts for the total oxidation of naphthalene in dry and wet conditions, establishing the reaction temperature for total conversion to $\mathrm{CO}_{2}$ at $300^{\circ} \mathrm{C}$. To conclude, the combination of Pd-based nanoparticles with zeolites, Beta and ZSM-5, permits the total oxidation of naphthalene at substantially lower temperatures $\left(165^{\circ} \mathrm{C}\right)$ than many catalysts reported in the literature. 


\section{Conclusions}

Zeolites BETA and ZSM-5, silicoaluminophosphate molecular sieve, SAPO-5 and $\gamma$-alumina impregnated with Pd nanoparticles have been used as catalysts for the total oxidation of naphthalene. All the catalysts produced high activity for naphthalene conversion to $\mathrm{CO}_{2}$, with total conversion taking place between 165 and $180{ }^{\circ} \mathrm{C}$. Pd/BETA was the most active catalyst. Furthermore, all the catalysts have high stability because their properties remain largely unchanged after testing for several oxidation cycles. Time-on-line experiments have been used to test the stability of the catalysts. The Pd/ZSM-5 and Pd/BETA samples were stable after accelerated ageing time-on-line for 48 hat $250{ }^{\circ} \mathrm{C}$. Therefore, the use of Pd-based nanoparticles supported on zeolites (BETA or ZSM-5) could be potential options for the abatement of PAHs by catalytic oxidation.

\section{Acknowledgments}

The authors would like to thank the Spanish Ministerio de Ciencia e Innovación and PLAN E funds (Project CTQ2009-10813/PPQ) and Generalitat Valenciana and FEDER (PROMETEO/2009/047) for financial support.

F.J. Varela-Gandía thanks the University of Alicante for the PhD studentship. Á. BerenguerMurcia thanks the Spanish Ministry for Science and Innovation for a Ramon y Cajal fellowship (RyC 2009-03913). 


\section{References}

[1] B. Solsona, T. Garcia, R. Murillo, A.M. Mastral, E. Ntainjua Ndifor, C. E. Hetrick, M. D. Amiridis, S. H. Taylor, Top. Catal. 52 (2009) 492 -500.

[2] M.H. Yuan, C.Y. Chang, J.L. Shie, C.C. Chang, J.H. Chen, W.T. Tsai, J. Hazard. Mater. 175 (2010) 809-815.

[3] F. Diehl, J. Barbier Jr., D. Duprez, I. Guibard, G. Mabilon, Appl. Catal. B 95 (2010) 217227.

[4] B. Puertolas, B. Solsona, S. Agouram, R. Murillo, A.M. Mastral, A. Aranda, S.H. Taylor, T. Garcia, Appl. Catal. B 93 (2010) 395-405.

[5] A.M. Mastral, M.S. Callen, Environ. Sci. Technol. 34 (2000) 3051-3057.

[6] X. Zhang, S. Shen, L.E. Yu, S. Kawi, K. Hidajat, K.Y. Simon Ng, Appl. Catal., A 250 (2003) 341-352.

[7] J.I. Park, J.K. Lee, J. Miyawaki, S.H. Yoon, I. Mochida, J. Ind. Eng. Chem. 17 (2011) 271-276.

[8] E. N. Ndifor, T. Garcia, S. H. Taylor, Catal. Lett. 110 (2006) 125-128.

[9] S.C. Kim, S.W. Nahm, W.G. Shim, J.W. Lee, H. Moon, J. Hazard. Mater 141 (2007) 305314.

[10] E.N. Ndifor, S.H. Taylor, Top. Catal. 52 (2009) 528-541.

[11] C.C. Chang, C.Y. Chiu, C.Y. Chang, C.F. Chang, Y.H. Chen, D.R. Ji, Y.H. Yu, P.C. Chiang, J. Hazard. Mater 161 (2009) 287-293.

[12] L. Yu, X. Li, X. Tu, Y. Wang, S. Lu, J. Yan, J. Phys. Chem. A 114 (2010) 360-368.

[13] M.H. Yuan, Y.Y. Lin, C.Y. Chang, C.C. Chang, J.L. Shie, C.H. Wu, IEEE Transactions On Plasma Science 39 (2011) 1092-1098.

[14] S.C. Marie-Rose, T. Belin, J. Mijoin, E. Fiani, M. Taralunga, F. Nicol, X. Chaucherie, P. Magnoux, Appl. Catal. B 90 (2009) 489-496.

[15] A. Bampenrat, V. Meeyoo, B. Kitiyanan, P. Rangsunvigit, T. Rirksomboon, Catal. Commun. 9 (2008) 2349-2352.

[16] T. Garcia, B. Solsona, D. Cazorla-Amorós, Á. Linares-Solano, S.H. Taylor, Appl. Catal., B 62 (2006) 66-76.

[17] T. Garcia, B. Solsona, S.H. Taylor, Appl. Catal., B 66 (2006) 92-99.

[18] A. K. Neyestanaki, L.E Lindfors, T. Ollonqvist, J. Väyrynen, Appl. Catal. A 196 (2000) 233-246. 
[19] M. Moreno-Mañas, R. Pleixats, Acc. Chem. Res. 36 (2003) 638-643.

[20] T. Teranishi, M. Miyake, Chem. Mater. 10 (1998) 594-600.

[21] S. Domínguez-Domínguez, Á. Berenguer-Murcia, D. Cazorla-Amorós, Á. LinaresSolano, J. Catal. 243 (2006) 74-81.

[22] S. Domínguez-Domínguez, Á.Berenguer-Murcia, B.K. Pradhan, Á.Linares-Solano, D.Cazorla-Amorós, J. Phys. Chem. C 112 (2008) 3827-3834.

[23] S. Domínguez-Domínguez, Á. Berenguer-Murcia, Á. Linares-Solano, D. CazorlaAmorós, J. Catal. 257 (2008) 87-95.

[24] I. Miguel-García, Á. Berenguer-Murcia, D. Cazorla-Amorós, Appl. Catal. B 98 (2010) 161-170.

[25] J.M. López, M.V. Navarro, T. García, R. Murillo, A.M. Mastral, F.J. Varela-Gandía, D. Lozano-Castelló, A. Bueno-López, D. Cazorla-Amorós, Microporous Mesoporous Mater. 130 (2010) 239-247.

[26] J.M. Campelo, F. Lafont, J.M. Marinas, J. Catal. 156 (1995) 11-18.

[27] D. Lozano-Castelló, F. Suárez-García, D. Cazorla-Amorós, Á. Linares-Solano, in: F. Beguin, E. Frackowiak (Eds), Carbon Materials for Electrochemical Energy Storage Systems, CRC Press, Boca Raton (US), 2010, p. 115-162

[28] K. S. W. Sing, D. H. Everett, R. A. W. Haul, L. Moscou, R. A. Pierotti, J. Rouquerol, T. Siemieniewska, Pure \& App. Chem. 57 (1985) 603-619.

[29] Boudart, Kinetics of Heterogeneous Catalytic Reactions, Princeton Univ.Press, Princeton, NJ, 1984.

[30] E. Ntainjua, A.F. Carley, S.H. Taylor, Catal. Today 137 (2008) 362-366.

[31]Y. Borodko, S.E. Habas, M. Koebel, P. Yang, H. Frei, G.A. Somorjai, J. Phys. Chem. B 110 (2006) 23052-23059.

[32] Y. Borodko, S.M. Humphrey, T.D. Tilley, H. Frei, G.A. Somorjai, J. Phys. Chem. C. 111 (2007) 6288-6295.

[33] J.K. Navin, M.E. Grass, G.A. Somorjai, A.L. Marsh, Anal. Chem. 81 (2009) 6295-6299.

[34] J. Shie, C. Chang, J. Chen, W. Tsai, Y. Chen, C. Chiou, C. Chang, Appl. Catal. B 58 (2005) 289-297.

[35] J. Park, J. Lee, J. Miyawaki, W. Pang, S. Yoon, I. Mochida, Catal. Commun. 11 (2010) 1068-1071. 


\section{FIGURE CAPTIONS}

Figure 1. TEM images and particle size distribution of: (A) colloid; (B) Pd/BETA; (C) Pd/ZSM-5; (D) Pd/SAPO-5; (E) Pd/ $\gamma-\mathrm{Al}_{2} \mathrm{O}_{3}$.

Figure 2.Variation of the amount of naphthalene adsorbed as a function of temperature on the three catalysts.

Figure 3.Variation of the catalytic activity for naphthalene oxidation (expressed as yield to $\mathrm{CO}_{2}$ ) as a function of reaction temperature over the four catalysts. (A) Pd/BETA; (B) Pd/ZSM-5; (C) Pd/SAPO-5; (D) $\mathrm{Pd} / \gamma-\mathrm{Al}_{2} \mathrm{O}_{3}$.

Figure 4. TEM images and particle size distribution of catalysts used after four cycles of naphthalene oxidation: (A) Pd/BETA; (B) Pd/ZSM-5; (C) Pd/SAPO-5; (D) Pd/ $\gamma-\mathrm{Al}_{2} \mathrm{O}_{3}$.

Figure 5. Conversion of naphthalene to $\mathrm{CO}_{2}$ as a function of time-on-line at $250^{\circ} \mathrm{C}$ for the Pd/BETA catalyst.

\section{TABLE CAPTIONS}

Table 1. Porous texture characterization of the supports and prepared catalyst.

Table 2.Nanoparticles sizes obtained from TEM data and metal loading of the different catalysts.

Table 3. Temperature required for naphthalene total oxidation for the different catalysts for the four oxidation cycles tested and coke deposition after 4 cycles.

Table 4. Turnover frequency (TOF) at $125^{\circ} \mathrm{C}$ and apparent activation energy for the four catalysts at first reaction cycle. 
Table 5. $\mathrm{CO}_{2}$ conversion at $150^{\circ} \mathrm{C}$ for the four catalysts and during the four cycles tested.

Table 6. Results of Pd nanoparticle analysis by TEM for catalysts after testing in naphthalene oxidation.

Table 7. XPS analysis of the four catalysts used, before and after use for naphthalene oxidation. 

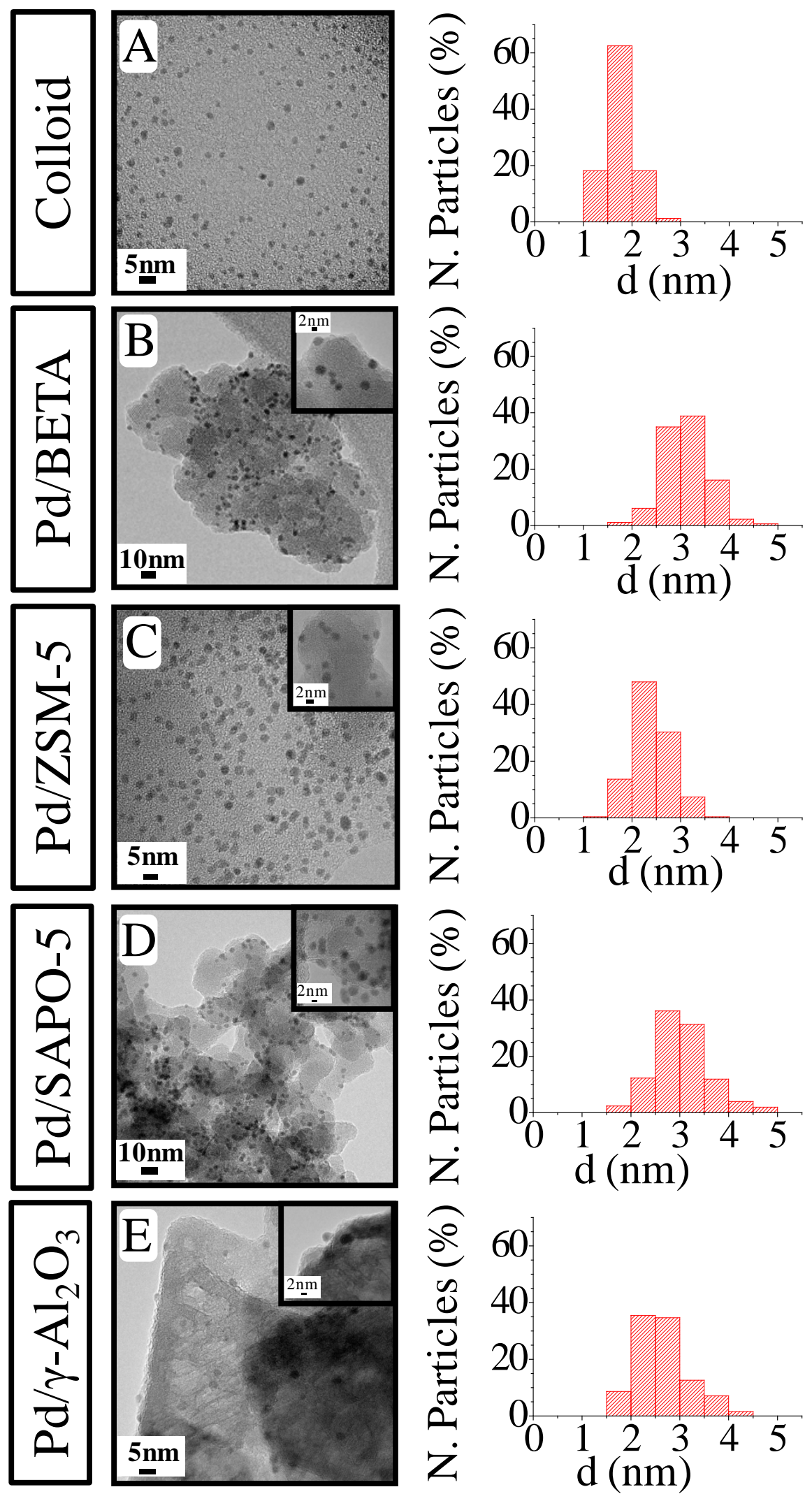

Figure 1. TEM images of: (A) colloid; (B) Pd/BETA; (C) Pd/ZSM-5; (D) Pd/SAPO-5; (E) $\mathrm{Pd} / \gamma-\mathrm{Al}_{2} \mathrm{O}_{3}$. 


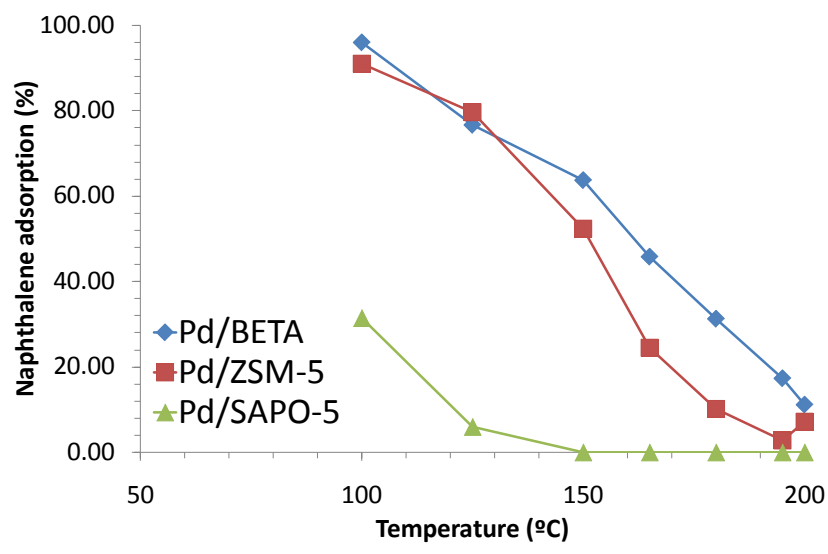

Figure 2. Variation of the amount of naphthalene adsorbed as a function of temperature on the three catalysts. 

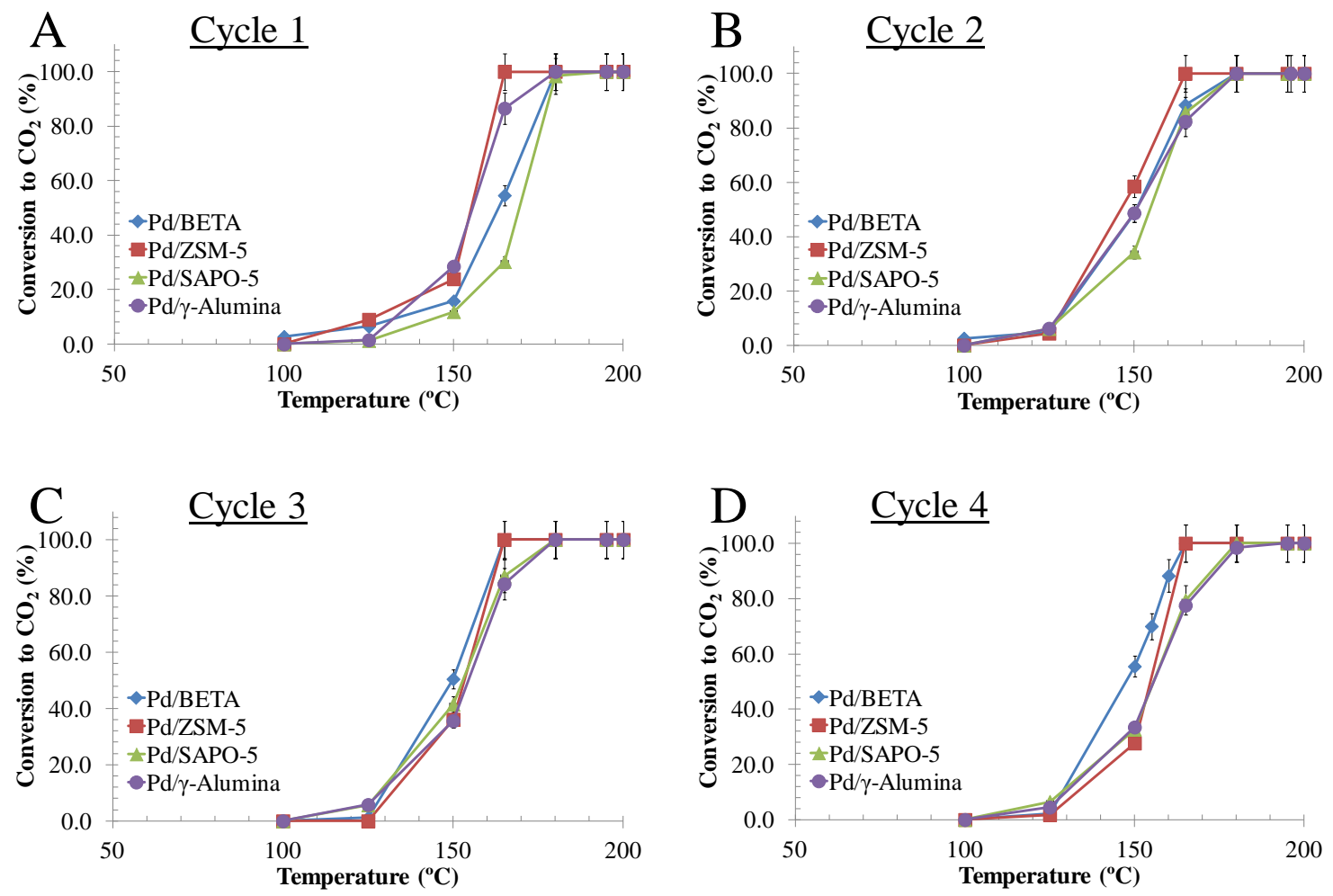

Figure 3.Variation of the catalytic activity for naphthalene oxidation (espressed as yield $\underline{\text { to } \mathrm{CO}_{2}}$ ) as a function of reaction temperature over the four catalyst. (A) cycle $1 ;$ (B) cycle 2; (C) cycle 3; (D) cycle 4. 

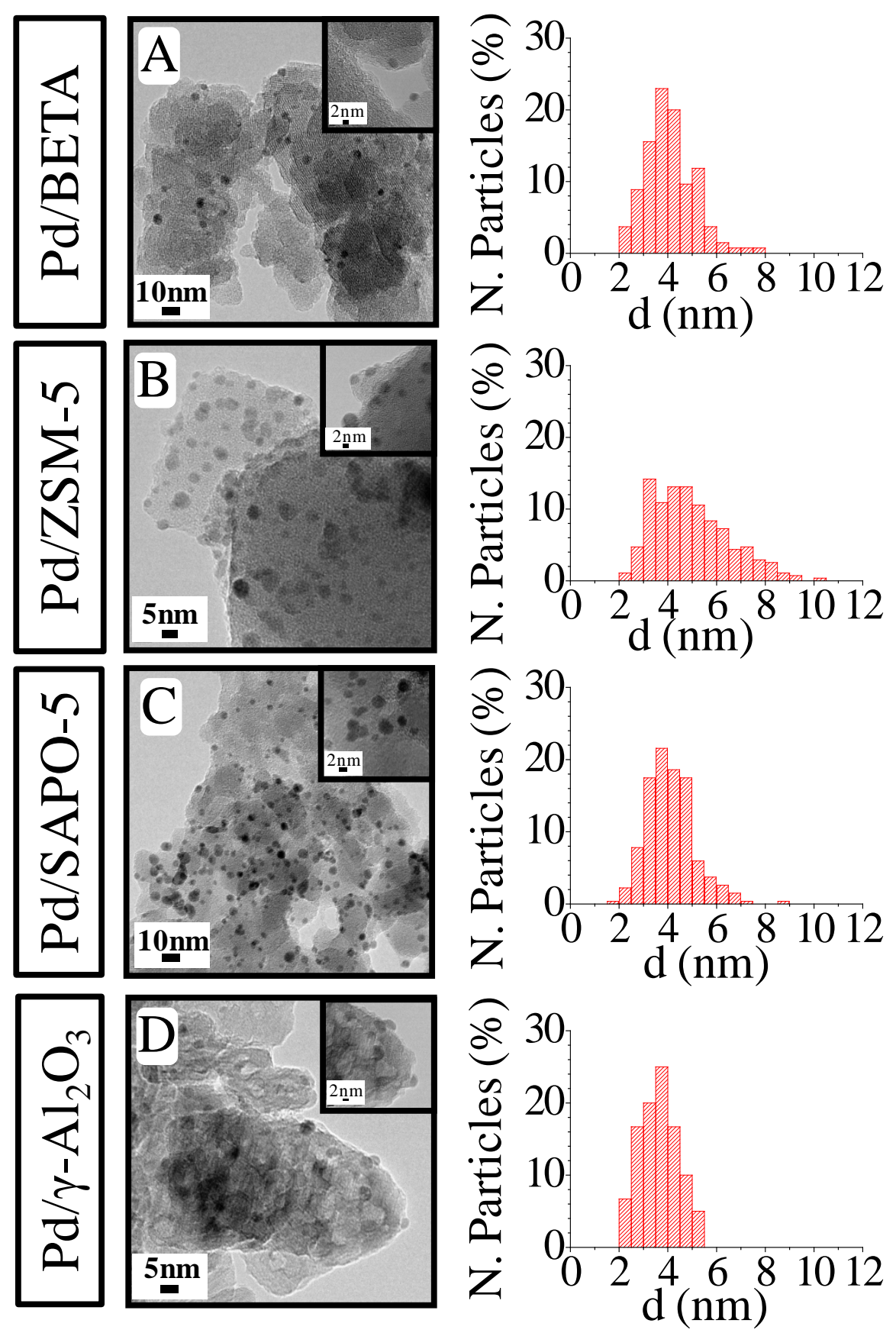

Figure 4. TEM images of tested catalyst after four cycles: (A) Pd/BETA; (B) Pd/ZSM5; (C) Pd/SAO-5; (D) Pd/ $\gamma-\mathrm{Al}_{2} \underline{\mathrm{O}_{3}}$. 


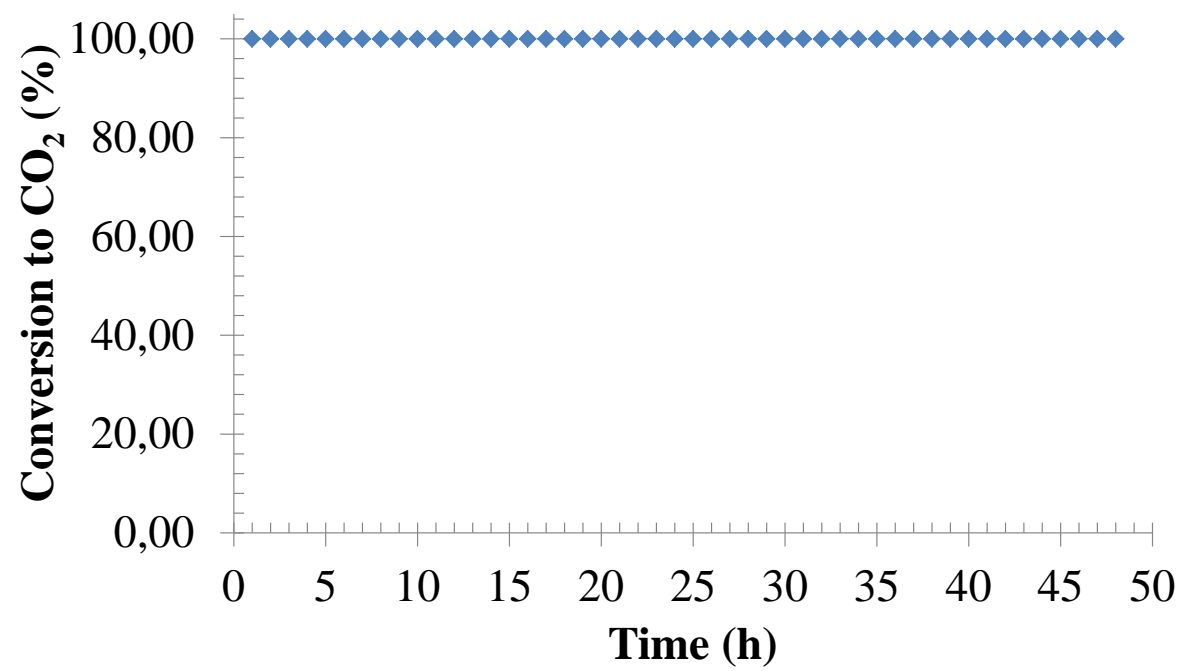

Figure 5. Time on line experiment for Pd/BETA catalyst. 
Table 1. Porous texture characterization of the supports and prepared catalyst.

\begin{tabular}{lccc}
\hline \multicolumn{1}{c}{ Sample } & $\boldsymbol{S}_{\mathbf{B E T}}\left(\mathbf{m}^{2} / \mathbf{g}\right)$ & $\boldsymbol{V}_{\mathbf{D R}}\left(\mathbf{N}_{\mathbf{2}}\right) \mathbf{( \mathbf { m l } / \mathbf { g } )}$ & $\boldsymbol{V}_{\mathbf{D R}}\left(\mathbf{C O}_{\mathbf{2}}\right)(\mathbf{m l} / \mathbf{g})$ \\
\hline BETA & 570 & 0.25 & 0.21 \\
Pd/BETA & 510 & 0.22 & 0.18 \\
\hline ZSM-5 & 290 & 0.14 & 0.11 \\
Pd/ZSM-5 & 270 & 0.12 & 0.11 \\
\hline SAPO-5 & 210 & 0.10 & 0.18 \\
Pd/SAPO-5 & 105 & 0.07 & 0.13 \\
\hline$\gamma$-alumina & 70 & 0.03 & 0.03 \\
Pd/ $\gamma$-alumina & 50 & 0.02 & 0.02 \\
\hline
\end{tabular}


Table 2.Nanoparticle sizes obtained from TEM data and metal loading of the different catalysts.

\begin{tabular}{|c|c|c|c|}
\hline Sample & $d$ TEM (nm) & $\begin{array}{c}\text { D TEM } \\
(\%)\end{array}$ & Metal loading (\%) \\
\hline Pd/BETA & $3.1 \pm 0.5$ & 29 & 0.54 \\
\hline $\mathrm{Pd} / \mathrm{ZSM}-5$ & $2.4 \pm 0.4$ & 38 & 0.74 \\
\hline Pd/SAPO-5 & $3.1 \pm 0.6$ & 29 & 0.74 \\
\hline $\mathrm{Pd} / \gamma-\mathrm{Al}_{2} \mathrm{O}_{3}$ & $2.6 \pm 0.2$ & 35 & 0.38 \\
\hline
\end{tabular}


Table 3.Naphtalene total oxidation temeprature for the four catalysts and during the four cycles tested.

\begin{tabular}{|c|c|c|c|c|c|}
\hline & \multicolumn{4}{|c|}{$\mathrm{T}\left({ }^{\circ} \mathrm{C}\right)$ for total conversion to $\mathrm{CO}_{2}$} & \multirow{2}{*}{$\begin{array}{l}\text { Coke deposited } \\
\text { (\%) after } 4 \\
\text { cycles }\end{array}$} \\
\hline Sample & $\begin{array}{c}\text { Cycle } \\
1\end{array}$ & $\begin{array}{c}\text { Cycle } \\
2\end{array}$ & $\begin{array}{c}\text { Cycle } \\
3\end{array}$ & $\begin{array}{c}\text { Cycle } \\
4\end{array}$ & \\
\hline Pd/BETA & 180 & 180 & 165 & 165 & 3.3 \\
\hline Pd/ZSM-5 & 165 & 165 & 165 & 165 & 0.8 \\
\hline $\mathrm{Pd} / \mathrm{SAPO}-5$ & 195 & 180 & 180 & 180 & 1.2 \\
\hline $\mathrm{Pd} / \gamma-\mathrm{Al}_{2} \mathrm{O}_{3}$ & 180 & 180 & 180 & 195 & 0 \\
\hline
\end{tabular}


Table 4.

\begin{tabular}{lcc}
\cline { 2 - 3 } & \multicolumn{2}{c}{ CYCLE 1} \\
\hline Sample & TOF $\left(\mathrm{s}^{-1}\right)\left(\mathrm{T}=125^{\circ} \mathrm{C}\right)$ & $\mathrm{E}_{\mathrm{a}}(\mathrm{KJ} / \mathrm{mol})$ \\
\hline $\mathrm{Pd} / \mathrm{BETA}$ & 0.075 & 46 \\
$\mathrm{Pd} / \mathrm{ZSM}-5$ & 0.056 & 55 \\
$\mathrm{Pd} / \mathrm{SAPO}-5$ & 0.010 & 126 \\
$\mathrm{Pd} / \gamma-\mathrm{Al}_{2} \mathrm{O}_{3}$ & 0.019 & 166 \\
\hline $0.5 \% \mathrm{Pt} / \mathrm{SiO}_{2}[30]$ & 0.0007 & -- \\
\hline
\end{tabular}


Table 6. TEM results and metal loading of the different catalysts.

\begin{tabular}{lcc}
\hline \multicolumn{1}{c}{ Sample } & $d$ TEM $(\mathrm{nm})$ & $\begin{array}{c}D \text { TEM } \\
(\%)\end{array}$ \\
\hline Pd/BETA & $4.1 \pm 1.0$ & 22 \\
Pd/ZSM-5 & $5.0 \pm 1.5$ & 18 \\
$\mathrm{Pd} / \mathrm{SAPO}-5$ & $4.1 \pm 1.0$ & 22 \\
$\mathrm{Pd} / \gamma-\mathrm{Al}_{2} \mathrm{O}_{3}$ & $3.6 \pm 0.7$ & 25 \\
\hline
\end{tabular}


Table 7. XPS anayles of the four catalysts used, before and after the experiment.

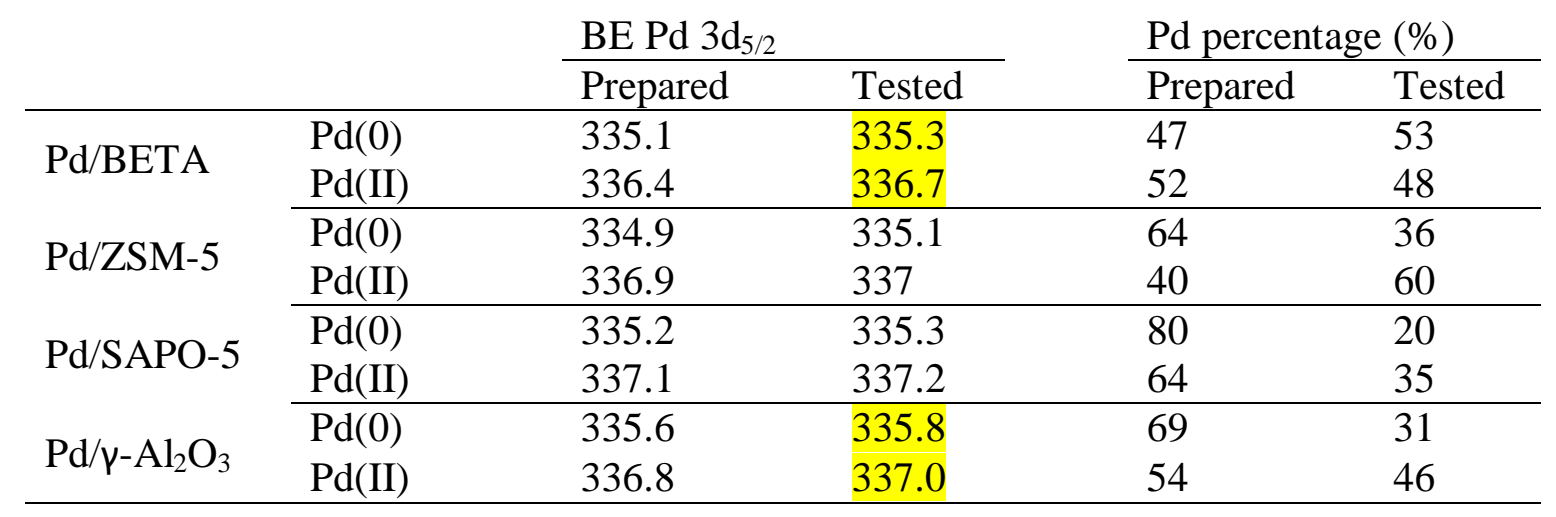

